\title{
RADIX: a minimal-resources rapid-access drilling system
}

\author{
J. SCHWANDER, S. MARENDING, T.F. STOCKER, H. FISCHER \\ Climate and Environmental Physics, Physics Institute, University of Bern, Bern, Switzerland \\ Oeschger Centre for Climate Change Research, University of Bern, Switzerland \\ E-mail: schwander@climate.unibe.ch
}

\begin{abstract}
Determining the expected age at a potential ice-core drilling site on a polar ice sheet generally depends on a combination of information from remote-sensing methods, estimates of current accumulation and modelling. This poses irreducible uncertainties in retrieving an undisturbed ice core of the desired age. Although recently perfected radar techniques will improve the picture of the ice sheet below future drilling sites, rapid prospective drillings could further increase the success of deep drilling projects. Here we design and explore a drilling system for a minimum-size rapid-access hole. The advantages of a small hole are the low demand for drilling fluid, low overall weight of the equipment, fast installing and de-installing and low costs. We show that, in theory, drilling of a $20 \mathrm{~mm}$ hole to a depth of $3000 \mathrm{~m}$ is possible in $\sim 4$ days. First concepts have been realized and verified in the field. Both the drill cuttings and the hole itself can be used to characterize the properties of the ice sheet and its potential to provide a trustworthy palaeo-record. A candidate drilling site could be explored in $\sim 2$ weeks, which would enable the characterization of several sites in one summer season.
\end{abstract}

KEYWORDS: glaciological instruments and methods, ice coring

\section{INTRODUCTION}

The aim of the RADIX (Rapid Access Drilling and Ice eXtraction) project is to design and construct fast-access icedrilling equipment for prospecting a potential drilling site in Antarctica in the framework of the International Partnership for Ice Core Sciences (IPICS) 'Oldest Ice Project' (http:// www.pages.unibe.ch/ipics/white-papers). The goal of this project is to drill an ice core providing a continuous undisturbed climate record over the past $1.5 \times 10^{6}$ years. The search for an optimal drilling site includes standard procedures such as airborne radar surveys and glaciological modelling (Fischer and others, 2013). For the first time, these pre-investigations will also be supplemented by fast-access drillings, which should increase the probability of the scientific success of the deep drilling project. The need for fast-access drilling is clearly indicated by the experience from past deep ice-core drilling projects, where folded ice and disturbed chronological sequences were encountered near the base of the ice sheet. This folding can comprise up to $10 \%$ of the ice-sheet thickness.

A fast-access system should ideally exceed the drilling speed of a large coring project by at least an order of magnitude, which would enable the survey of several sites in one season. This requires an optimization of the size and set-up of the equipment and a minimization of the hole size in order to reduce weight, drill fluid consumption and to save time for moving the equipment to the next site.

The type of prospective drilling depends largely on the scientific goals. The range is from boring an access hole to carry out measurements in the borehole, to retrieving ice cores from specific depths or from the full length. It could include logging-while-drilling instruments. Our aim is to develop a system using minimal resources and logistics support. In order to keep the total weight low, while attempting a reasonable drilling speed, we focus on a very small hole diameter and refrain from collecting cores, although drilling of short core sections could be a practicable option. For our RADIX project we decided to use a miniaturized version of a coiled tubing drilling system (Clow and Koci, 2002). The advantage of this technique is the simplicity of the components and the use of a hydraulic motor providing high torque at small diameters.

Design work on RADIX started in summer 2012. After the prototyping phase, the final goal will be to drill several holes at potential deep drilling sites down to or near to bedrock. The holes will be used for temperature and other downhole measurements. The drilled ice chips and/or core samples from specific depths will be analyzed, with the main goal to determine the age of the ice near the bottom and to assure the integrity of the ice-core record.

\section{DRILLING APPROACH}

Our design is based on the established technique of coiled tubing drilling (Clow and Koci, 2002) in forward flow mode. A downhole hydraulic motor is powered by high-pressure fluid in the coiled tubing/hose, and cuttings are flushed to the surface along the space between the hole wall and the tubing/hose. The goal is to optimize the system for low weight and speed of penetration. The drilling fluid also serves to maintain a balanced hydrostatic pressure in the hole. The fluid represents a significant part of the total weight and cost of a drilling (Fig. 1). Therefore we set minimizing the hole size as a major constraint of the design. Hole size, hydraulic hose dimensions, hydraulic pressures, power for drilling, drilling speed, etc., are closely interrelated. We first determine some constraints.

Drill speed $v$ : We aim at prospecting a site within 2 weeks, where $\sim 1$ week is allocated to drilling and $\sim 1$ week to measurements. The maximum required depth is $3000 \mathrm{~m}$, as thicker ice will most likely be subject to bottom melting (Fischer and others, 2013). Taking into account some days for setting up and interruptions we plan for an effective drilling time of 4 days, corresponding to a drilling speed of nearly $10 \mathrm{~mm} \mathrm{~s}^{-1}$. 


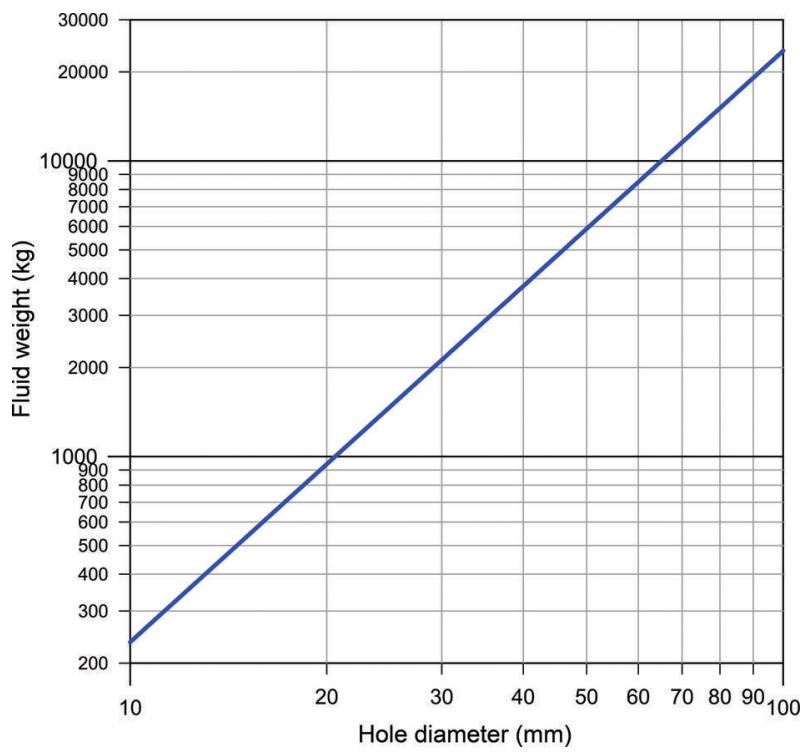

Fig. 1. Drilling fluid demand for a $3000 \mathrm{~m}$ hole based on density $930 \mathrm{~kg} \mathrm{~m}^{-3}$ (without losses).

Downhole pressure $p_{\mathrm{o}}$ : The pressure external to the hydraulic hose must not stress the ice beyond the tensile strength, to avoid fracking of the ice, which would probably be associated with a substantial loss of fluid. As the maximum tangential stress in a cylindrical hole within an infinite isotropic body is equal to the differential pressure between the hole and a point far away (Timoshenko and Goodier, 1970), the pressure in the hole must not exceed the tensile strength of the ice. The tensile strength of polycrystalline ice is on the order of $1 \mathrm{MPa}$. However, especially at low strain rates, crack formation could already be initiated at much lower overpressures (Schulson and Duval, 2009). To avoid fracking it is advisable to keep the static pressure in the hole somewhat below the hydrostatic pressure of the ice. Tolerating 0.5 MPa overpressure at the bottom while drilling and keeping the static pressure $1 \mathrm{MPa}$ below hydrostatic allows a pressure drop in the annular upward flow of up to 1.5 MPa.

Hydraulic pump pressure $p_{s}$ : In order to use relatively lightweight ordinary hydraulic equipment we restrict the maximum pressure to $20 \mathrm{MPa}$.

Fluid viscosity $\eta$ : A low fluid viscosity is essential in view of the long flow paths and the envisaged small hole size. We plan to use a similar fluid to that suggested for other ice-drilling operations such as Estisol 140 or Silicone fluid (Talalay, 2011) with an average dynamic viscosity of $\leq 5 \mathrm{mPa}$.

Ice chips/fluid mixing ratio $x$ : As we expect the upward transport of chips to be one of the most crucial issues of the project, we aim at a relatively diluted slurry and set the chips/fluid mixing ratio arbitrarily to $10 \%$. We expect the viscosity of the slurry to be $\sim 1.35$ times the viscosity of the pure fluid (Thomas, 1965).

The remaining parameters of the hydraulic system are constrained by the physical laws. Variables used in the derivations below are summarized in Table 1.

The output power $P$ of the motor is given by

$$
P=J\left(p_{\mathrm{m}}-p_{\mathrm{o}}\right) \gamma
$$

Table 1. Hydraulic system parameters used to determine the minimal drillhole diameter. Pressures are relative to the hydrostatic pressure

\begin{tabular}{lcc}
\hline Parameter & Description & Prescribed value \\
\hline$v$ & Drilling speed & $0.01 \mathrm{~m} \mathrm{~s}^{-1}$ \\
$H$ & Max. hole depth & $3000 \mathrm{~m}$ \\
$p_{\mathrm{o}}$ & Pressure at bottom & $1.5 \mathrm{MPa}$ \\
$p_{\mathrm{s}}$ & Fluid pressure at surface & $<20 \mathrm{MPa}$ \\
$x$ & Chips/fluid mixing ratio & $1 / 10$ \\
$\eta$ & Viscosity & $5 \times 10^{-3} \mathrm{~Pa} \mathrm{~s}$ \\
$d_{\mathrm{i}}$ & Tubing inner diameter & \\
$d_{\mathrm{o}}$ & Tubing outer diameter & \\
$d_{\mathrm{h}}$ & Hole diameter & \\
$J$ & Fluid flow rate & \\
$p_{\mathrm{m}}$ & Fluid pressure drop at motor \\
$P$ & Motor power (output) \\
&
\end{tabular}

Tests with a prototype motor have shown that we can expect a motor efficiency $\gamma$ of $\sim 30 \%$.

From deep drilling operations we estimate that $\sim 10 \mathrm{MJ}$ of energy are used to produce $1 \mathrm{~m}^{3}$ of cuttings (Gundestrup and others, 1994). This energy includes the energy for cutting the ice and the energy for the transport of the ice chips and frictional losses. As we will produce finer cuttings than with a regular core drill, we use here a conservative value of $20 \mathrm{MJ} \mathrm{m}^{-3}$ for the specific cutting energy $E$.

The required motor power $P$ is therefore

$$
P=v d_{\mathrm{h}}^{2} \pi \frac{E}{4}
$$

The pressure loss in the hose is given by

$$
p_{\mathrm{s}}-p_{\mathrm{m}}=\frac{128 / H \eta}{\pi d_{\mathrm{i}}^{4}}
$$

The laminar flow assumption used here is justified by the resulting Reynolds numbers. The pressure loss in the annulus depends on the position of the hose relative to the centre of the hole. The flow is easier in an eccentric annulus (Piercy and others, 1933). As we expect that the hole will not be exactly vertical but will have an inclination of a few degrees, we can safely assume that the hose will generally be in a full eccentric position. The enhancement factor compared to concentric flow depends slightly on the hole/ hose diameter ratio, but is $\sim 2.2$ for the range of practical diameters. We further assume that the effective viscosity of the fluid with cuttings is $35 \%$ higher than that of the pure fluid (Thomas, 1965).

According to Piercy and others (1933), the pressure loss in the annulus between $d_{\mathrm{o}}$ and $d_{\mathrm{h}}$ is given by

$$
p_{\mathrm{o}}=\frac{128 J(1+x) H \cdot 1.35 \eta}{2.2 \pi\left(d_{\mathrm{h}}^{4}-d_{\mathrm{o}}^{4}+\frac{\left(d_{\mathrm{h}}^{2}-d_{\mathrm{o}}^{2}\right)^{2}}{\ln \left(d_{\mathrm{o}} / d_{\mathrm{h}}\right)}\right)}
$$

where

$$
x=\frac{v d_{\mathrm{h}}^{2} \pi}{4 J}
$$

is the ratio between the volume flow rates of newly drilled ice and recirculated fluid.

This set of equations describes the characteristics of the system with two free parameters. Figure 2 shows the numerical solution of the required pump pressure as a function of hole diameter for three different tubing wall thicknesses. 


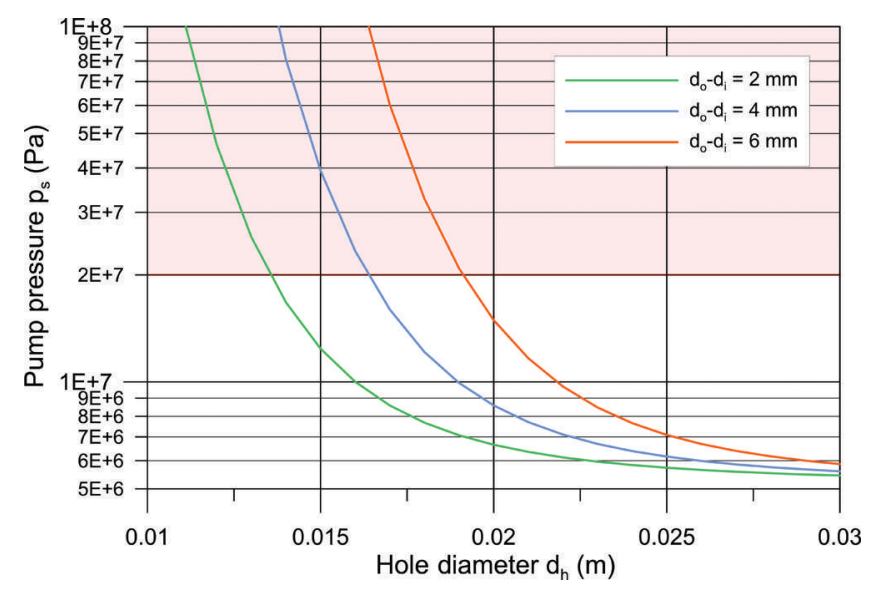

Fig. 2. Numerical solution of Eqns (4) and (5) for tubing wall thickness of 1, 2 and $3 \mathrm{~mm}$. In the red shaded area the required pump pressure exceeds the specified maximum of $20 \mathrm{MPa}$.

This theoretical basis shows the practical lower limit of the diameter that can potentially be realized by a coiled tubing drill to a depth of $3000 \mathrm{~m}$. The $1 \mathrm{~mm}$ wall thickness corresponds to a reasonable dimension of steel tubing, while the $3 \mathrm{~mm}$ wall thickness is typical for a plastic hydraulic pressure hose. With a $7 \mathrm{~mm}$ outer diameter (o.d.) steel tubing one could drill a hole as small as $14 \mathrm{~mm}$. The weight of the tubing in the fluid would be $\sim 3500 \mathrm{~N}$, requiring a sophisticated tubing guide and injectors. The lower limit when using a plastic hydraulic hose with a $3 \mathrm{~mm}$ wall is $\sim 20 \mathrm{~mm}$. A metal-free hydraulic hose can be manufactured with a specific weight very close to that of ice, making it nearly weightless when immersed in a fluid matching the ice density. The main disadvantage of the plastic hose is its larger elasticity compared to steel, making penetration control more difficult. Nevertheless, in order to minimize size, complexity and weight, we have decided to pursue only the metal-free hydraulic hose version.

Aiming at a $20 \mathrm{~mm}$ hole and a hose with $3 \mathrm{~mm}$ wall thickness we obtain the following values for the remaining system parameters:

Flow rate $J=31.5 \mathrm{~mL} \mathrm{~s}^{-1}$

Fluid pressure at surface $p_{\mathrm{s}}=17.3 \mathrm{MPa}$

Hose inner/outer diameter $d_{\mathrm{i}} / d_{\mathrm{O}}=6.35 / 12.35 \mathrm{~mm}$

Motor power $P=63 \mathrm{~W}$

Pressure drop at motor $p_{\mathrm{m}}=5.7 \mathrm{MPa}$

\section{DRILLING COMPONENTS}

To engineer such a targeted miniature coiled tubing drill, the following major components need to be evaluated/designed (Fig. 3):

1. Micro hydraulic motor fitting into a $20 \mathrm{~mm}$ hole

2. Hydraulic hose

3. High-pressure pump

4. Spooling and feeding system for the hose

5. Drilling fluid

6. Chips/fluid separation and fluid recycling system

7. Firn casing and drilling system through the firn layer

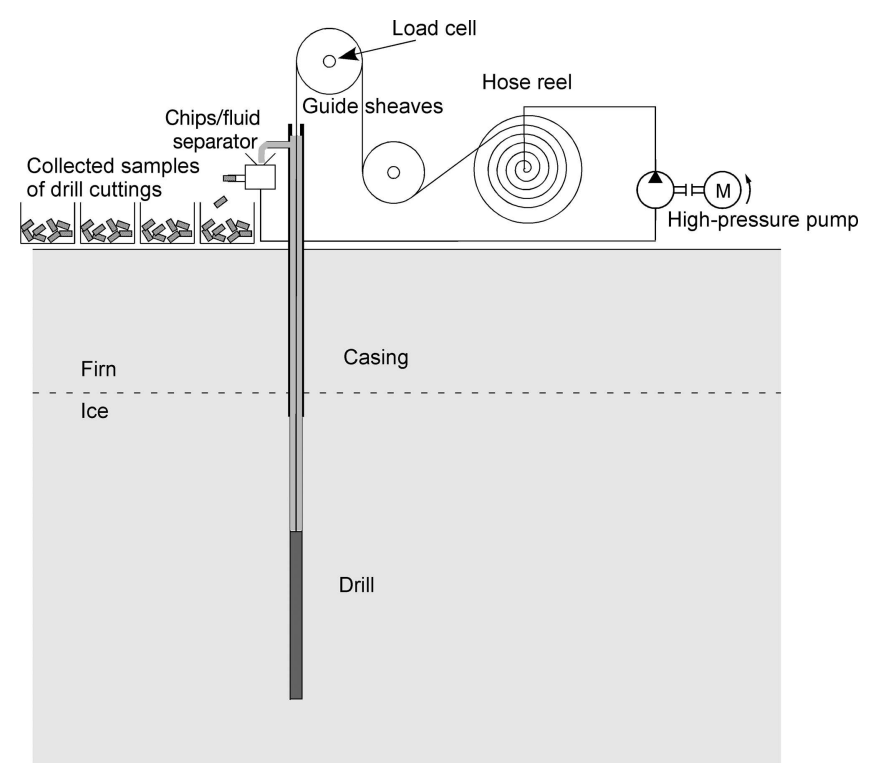

Fig. 3. Principal components of the rapid-access drilling system.

Here we discuss the fundamental parts of the drill and some aspects of their design.

\section{Hydraulic motor and drill bit}

We are not aware of a commercial drive unit with a diameter in the order of $15 \mathrm{~mm}$. The smallest mud motors on the market have a diameter of $43 \mathrm{~mm}$. We have decided to design a tailored micro-motor based on the Moineau design (progressive cavity motors (Moineau, 1931)) offering a very slim, robust and mechanically simple device (Fig. 4). Most Moineau motors use a stator made of rubber. The very low temperatures and the use of a yet unknown, potentially aggressive drilling fluid make the use of elastomers unfeasible. Therefore a full metal design is preferred. The geometry of stator and rotor is rather complex and requires high machining quality (in the order of $0.01 \mathrm{~mm}$ ) in order to keep the leak rate of the low-viscosity hydraulic fluid in a tolerable range. Conventional machining (milling, microspark erosion) is rather costly, especially in the prototyping phase when several versions may be required to optimize the design. The small size of the motor and the complex geometry are an ideal application for three-dimensional (3-D) metal printing (Fig. 5; Ecoparts, Switzerland). However, the surface roughness of the laser sintered parts $(\sim 20 \mu \mathrm{m})$ is not sufficient. By carefully adjusting the dimensions of rotor and stator they can be ground against each other using a $20 \mu \mathrm{m}$ grain-size finishing compound, resulting in a satisfactory leak rate for the viscosity range of potential fluids. We have run a first prototype motor for 7 hours using water as a fluid (viscosity $\sim 1 \mathrm{mPa}$ ) at a load of $\sim 30 \mathrm{~W}$. The performance was close to expectation. The leak rate was $\sim 50 \%$ and the overall efficiency $\sim 20 \%$. The leak rate increased by $\sim 40 \%$ during the test. These values will be better when using higher-viscosity fluids. Also the leak rate was not optimal because of a not yet optimized dimensioning of rotor and stator. In addition, the surfaces of those parts will be nitrided in order to reduce wear.

Specifications of the motor:

Type: Progressive cavity displacement, 3-4 lobe

Geometry: $15 \mathrm{~mm}$ diameter, $60 \mathrm{~mm}$ length, volume displacement $2.1 \mathrm{~cm}^{3} \mathrm{rev}^{-1}$ 


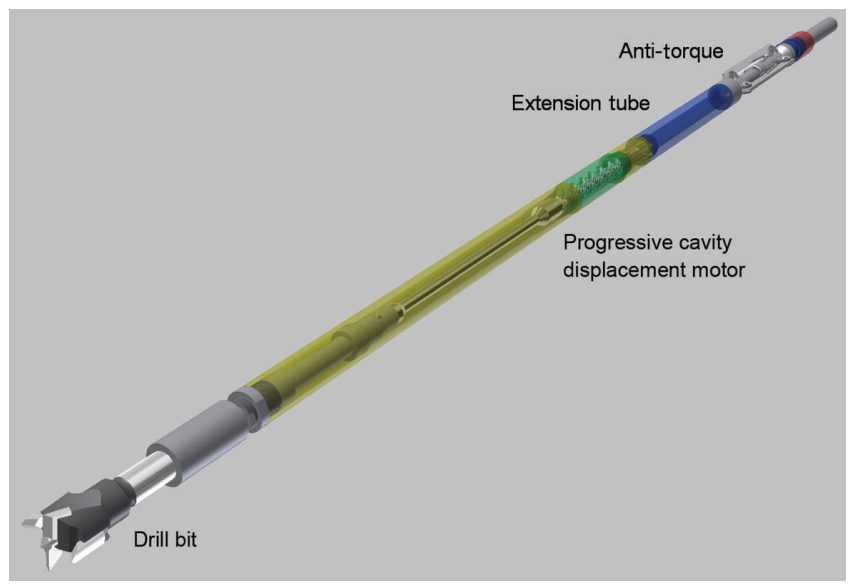

Fig. 4. Drill assembly.

\section{Nominal speed: $15 \mathrm{rps}$}

As drill bit we use a modified $20 \mathrm{~mm}$ carbide-tipped cylindrical wood boring bit (Oertli, Switzerland) with hard metal cutters. Supplemented bores allow fluid to flow to the cutters. Limiting bolts between the cutters have been added to control the pitch (nominal $0.6 \mathrm{~mm}$ ). To make the bit more aggressive the function of the 'pre-cutters' has been reduced to a guide element by grinding them back behind the main cutters. We plan for zero or slightly negative weight on the bit to facilitate vertical penetration.

Although the hose is strong enough to take the torque, a small anti-torque section on top of the drill reduces twisting of the hose. The verticality of the hole is controlled passively by gravity. An extension tube can be introduced between anti-torque section and drill to make verticality changes slower and to add some weight to the end of the hose to compensate for the drag that the upward-moving fluid exerts on the hose.

\section{Hydraulic pump and hose}

A triplex plunger type high-pressure pump (Speck, Germany) has been equipped with special seals and sleeves to resist most drilling fluids. The flow rate (nominal $5 \mathrm{~L} \mathrm{~min}^{-1}$ ) is adjustable with a frequency inverter controlled asynchronous three-phase motor. The outer and inner layer of a custom-made aramid reinforced hose (Kutting, UK) is made of nylon in order to resist most potential drilling fluids. The wall thickness is $3 \mathrm{~mm}$ and the inner diameter $6-8 \mathrm{~mm}$. The final size of the hose will be determined after first field tests.

\section{Casing of the firn layer}

The firn layer above the solid ice is permeable and needs to be cased. The hole through the firn layer is drilled with any available drilling technique (dry mechanical, hot water). As casing we plan to use a $21.3 / 28.3 \mathrm{~mm}$ polyethylene tube in a single piece. The bottom of the tube needs to be connected in a pressure-tight manner to the ice. This connection, which must withstand the pressure of an 80$100 \mathrm{~m}$ liquid column, will be made by melting and refreezing some ice at the bottom. The tightness will be tested with compressed air before filling the tube with fluid.

\section{Recycling of the drilling fluid}

With a mixing ratio between cuttings and fluid of $1: 10$, the drilling fluid is cycled about ten times through the hole. We

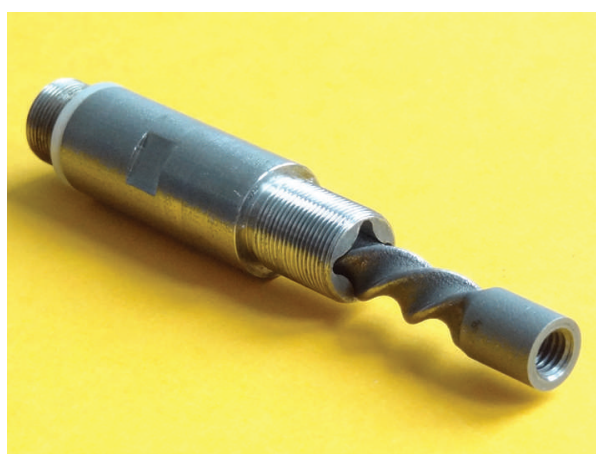

Fig. $5.15 \mathrm{~mm}$ diameter progressive cavity displacement rotary drive unit. The bodies except threads have been manufactured by 3-D direct metal laser sintering.

will collect the chips for scientific purposes (e.g. age determination) trying to keep an essentially undisturbed sequence. For this purpose we plan to stop the penetration every $100 \mathrm{~m}$ while keeping the fluid flowing in order to create some spacing between successive chips packets. A prerequisite for this approach is that the buoyancy-driven sedimentation speed of the chips is much smaller than the flow speed in the annulus. Assuming a chips size of $<0.5 \mathrm{~mm}$ in diameter and a density mismatch between fluid and ice of $<10 \mathrm{~kg} \mathrm{~m}^{-3}$, the sedimentation speed is expected to be more than two orders of magnitude smaller than the flow speed of the drilling fluid. A spacing distance between packets corresponding to a few per cent of the actual drilling depth should therefore be sufficient. We must evidently accept some mixing of the chips due to the velocity distribution arising from differential sedimentation and fluid flow speeds, and differences in friction between chips and hole wall. In order to keep a good sequence we also need to use a continuous separator for the chips. First tests with an extruder press look promising (Fig. 6). We will evaluate the possibility of removing the fluid from the hole and reusing it for several drillings.

\section{Spooling and feeding system for hose}

We are planning a simple motor-driven winch drum to lower and hoist the hose including guide wheels with an accurate load cell to monitor penetration of the drill. Owing to the light weight of the system, first tests to a maximum depth of $300 \mathrm{~m}$ will be made by manual feed and hoisting.

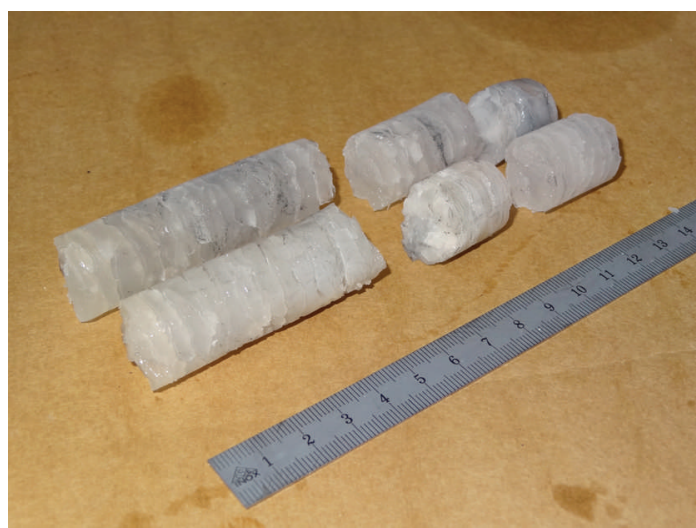

Fig. 6. Ice pellets extruded from ice/silicone oil slurry with a hand crank seed oil press have a residual oil content of $\sim 2 \%$. 


\section{USE OF THE ACCESS HOLE AND COLLECTED CUTTINGS}

The cuttings can be used for standard measurements such as water isotopic composition and trace component analysis (e.g. cosmogenic ${ }^{10} \mathrm{Be}$ and ${ }^{36} \mathrm{Cl}$ ), as long as these are not affected by the traces of drilling fluid, which in most cases can hardly be avoided. Gas measurements are obviously excluded because the cuttings are too small to retain undisturbed air samples. The size of the hole will accept small probes only. We think mainly of fiber-optic instruments, like distributed temperature sensing (DTS; Tyler and others, 2013) or dust measurements by light scattering (Bay and others, 2001). Technically a coring head could be used to retrieve bulk samples. However, the achievable core diameter would be barely more than $10 \mathrm{~mm}$ and the length rather limited. Rising and lowering of the drill would substantially extend the overall operation, so that such samples could only be taken from selected depths. The value of a coring option needs to be carefully evaluated against the increase in drilling time.

\section{FIELD TEST}

A first test was made on the temperate Glacier de la Plaine Morte, Switzerland, in summer 2013. Here we used a small commercial $21 \mathrm{~mm}$ o.d. Moineau pump (Allweiler, Germany) as a motor, with a $30 \mathrm{~mm}$ modified cylindrical drill bit. A high-pressure cleaner (Kärcher, Germany) was used to drive the drill with surface water from the glacier. Flow rates and pressures were similar to those in the system described above. The test has demonstrated the feasibility of the system. The penetration rate was close to the planned $10 \mathrm{~mm} \mathrm{~s}^{-1}$. However, the depth reached during the test was limited to $3.5 \mathrm{~m}$ due to clumping preventing chips from rising in the annulus. This was not surprising, as wet ice clumps very easily. We anticipate much less sticking with cold chips well diluted in a hydrophobic fluid.

\section{CONCLUSIONS}

We have investigated the minimum practical hole dimension that can be drilled through polar ice sheets. The feasibility of drilling a rapid-access hole of only $20 \mathrm{~mm}$ diameter with a coiled tubing method through the polar ice sheet has been shown in theory and partly in practice. Although not all parts of the equipment exist in hardware yet, we estimate a total weight of $\sim 2 t$ for the system including fluid for one hole. About $2 \mathrm{~kW}$ of electrical power will be required for drilling. We do not expect that drilling itself and fluid handling at the surface will raise major problems. More challenging is the slurry transport from the drill up to the surface, which has not yet been tested in practice. Indeed, this transport represents probably the most delicate and uncertain aspect of the system. A test drilling to $300 \mathrm{~m}$ is planned in Greenland. This should reveal whether the transport of cuttings in the annulus between hose and the hole wall is possible. Another issue that needs close attention is the loss of fluid by fracking of the ice due to overpressure in the hole. To be on the safe side it is advisable to keep the total pressure in the hole close to or slightly below the hydrostatic pressure, which requires a well-matched density and a low viscosity of the fluid.

\section{ACKNOWLEDGEMENTS}

This project would not have been possible without innumerable valuable discussions and exchanges within the international ice-drilling community. J.S. thanks Jeff Severinghaus for discussions on ice fracking. The project is supported by the Fondation d'entreprise AIR LIQUIDE.

\section{REFERENCES}

Bay RC, Price PB, Clow GD and Gow AJ (2001) Climate logging with a new rapid optical technique at Siple Dome. Geophys. Res. Lett., 28(24), 4635-4638 (doi: 10.1029/2001GL013763)

Clow GD and Koci B (2002) A fast mechanical-access drill for polar glaciology, paleoclimatology, geology, tectonics and biology. Mem. Natl Inst. Polar Res., Special Issue 56, 5-37

Fischer $\mathrm{H}$ and 23 others (2013) Where to find 1.5 million $\mathrm{yr}$ old ice for the IPICS 'Oldest-Ice' ice core. Climate Past, 9(6), 2489-2505 (doi: 10.5194/cp-9-2489-2013)

Gundestrup NS, Steffensen JP and Schwander J (1994) The GRIP deep drilling camp. Mem. Natl Inst. Polar Res., Special Issue 49, 358-370

Moineau, RJL (1931) Gear mechanism. US Patent No. 1892217 A

Piercy NAV, Hooper MS and Winny HF (1933) Viscous flow through pipes with cores. Philos. Mag., 15(99), 647-676 (doi: 10.1080/14786443309462212)

Schulson EM and Duval P (2009) Creep and fracture of ice. Cambridge University Press, Cambridge

Talalay PG (2011) Drilling fluids for deep coring in central Antarctica. (Tech. Rep. PRC 12-01) Polar Research Center, Jilin University

Thomas DG (1965) Transport characteristics of suspension: VIII. A note on the viscosity of Newtonian suspensions of uniform spherical particles. J. Colloid Sci., 20(3), 267-277 (doi: 10.1016/ 0095-8522(65)90016-4)

Timoshenko SP and Goodier JN (1970) Theory of elasticity. McGraw-Hill, New York

Tyler SW and 8 others (2013) Using distributed temperature sensors to monitor an Antarctic ice shelf and sub-ice shelf cavity. J. Glaciol., 59(215), 583-591 (doi: 10.3189/2013JoG12J207) 